\title{
Editors' introduction to spatial knowledge networks: structure, driving forces and innovative performances
}

\author{
Corinne Autant-Bernard • Nadine Massard • \\ Robin Cowan
}

Published online: 31 October 2014

(C) The Author(s) 2014. This article is published with open access at Springerlink.com

\section{Context: knowledge networks and the geography of innovation}

Knowledge networks have recently received increasing attention in the field of regional science. This is due to two changes in the interaction between geography and knowledge. First, there has been a change in the way knowledge is produced and diffused. Networking processes are increasingly involved in the production of knowledge. Moreover, several studies of scientific publications, patents and R\&D collaborations show that these networks are becoming increasingly complex and are characterised by an increasing number of agents, increased density and complexity within networks, and wider geographical distribution (Roijakkers and Hagedoorn 2006; Newman 2004; Powell et al. 2004; Wagner and Leydesdorff 2005; Cloodt et al. 2006).

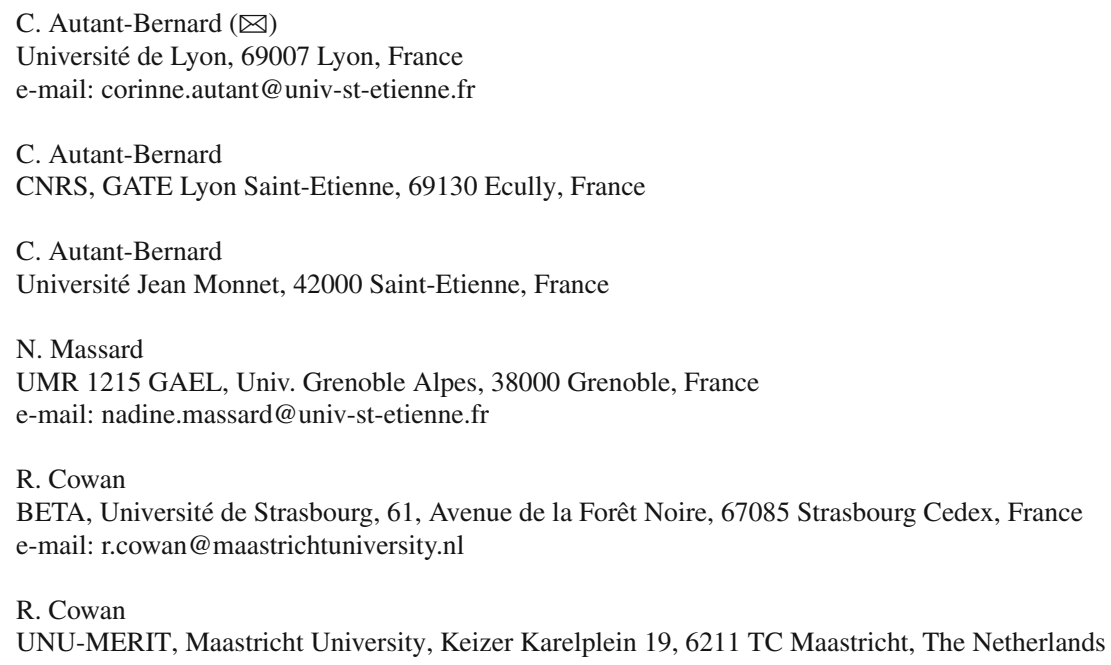


Secondly, recent empirical results in the field of the geography of innovation have pointed out the central role played by interpersonal relationships in knowledge diffusion. Breschi and Lissoni (2009), for example, show that networks of interpersonal relationships are the main vector for knowledge flows and their concentration in space explains the spatial agglomeration of innovation. Hence, in order to understand the determining factors of the geography of innovation, it is no longer simply a matter of measuring the extent of local knowledge externalities, in the sense of the unrestricted and uncompensated diffusion of knowledge, but rather it becomes necessary to understand the voluntary strategies used by those taking part in innovation to acquire knowledge from within the networks.

These two changes have thus opened the way for new research on how close and distant actors come together to produce and diffuse knowledge and how the resulting collaboration networks shape local performances.

The spatial dimension of collaborative networks has been at the heart of geographical analyses of innovation for almost a decade, and this literature has already drawn a certain number of conclusions: ${ }^{1}$

- the positive role of geographical proximity in choosing R\&D partnerships.

- the relative and sometimes secondary role of this geographical proximity compared to other forms of proximity (technological, organisational, institutional, cultural, etc.).

- the impact of participation in collaborative networks on innovative performance.

Despite this progress, significant challenges remain to understanding how these networks are formed on the one hand and the relationship between the structure of knowledge networks and innovative performance on the other.

\section{Driving forces of network formation and innovative performances: new research questions for regional sciences}

The research challenges are both methodological and analytical. From a methodological point of view, it is essential to go beyond the analysis of bilateral relationships in order to account for both the mechanisms by which networks are created and their impact upon performance. From a more analytical point of view, there is a need to provide a theoretical framework to represent the decision-making processes that underlie the formation of relationships and their economic implications.

\footnotetext{
1 A special Issue on 'Spatial econometrics, innovative networks and growth' edited by Autant-Bernard et al. (2007) appeared in The Annals of Economics and Statistics and The Annals of Regional Science published a special issue on this topic in 2009. Co-ordinated by E. Bergman and G. Maier (Bergman and Maier, 2009) this volume brought together contributions assessing two main issues: the impact of spatial distance on the diffusion of knowledge relative to other kinds of proximity and especially relative to social or relational proximity on the one hand, and the impact of spatial distance as a driver of knowledge network structure on the other. The first two European Seminars on the Geography of Innovation that were held in Saint Étienne in January 2012 and Utrecht in January 2014 also pointed to an increasing interest in spatial innovation networks.
} 
2.1 From the formation of relationships to the formation of networks: the structure and the position of actors

The regional sciences are confronted with two major questions in this regard: What different types of proximity are at work? Do the determinants of network formation (and particularly the role of various types of proximity) differ depending on the nature of the network?

A fairly extensive body of literature already exists on these questions, although earlier work focussed on exploring the impact of proximity on bilateral relationships. These studies encountered significant methodological challenges, however (an important example being the assumption that relationships are independent of one another), and they did not explore the structural characteristics of networks. Fairly diverse and undifferentiated information is used in isolation to represent knowledge networks (patents, publications, collaborative R\&D projects) from different public policy initiatives (European, national or local), leading to results which most often remain largely partial, ambiguous, and difficult to compare.

This special issue does not, therefore, aim to add to the abundant literature which already exists on the effects of proximity as a determinant of cooperative relationships between innovative actors ${ }^{2}$ but, in contrast, to address the methodological challenges in such a way as to identify, more specifically, the determinants of the structure of networks and the position of regions within them. In this special issue, the methodological contribution from Broekel et al. presents a panorama of the main statistical techniques for analysing networks used in the literature. Broekel et al. address the fact that the formation of links is not independent of the presence or absence of other (specific) links in the network and how this affects analyses of the dynamics of spatialised knowledge networks. The contribution from Hazir and Autant-Bernard loosens the methodological constraints of the independence of relationships to analyse the formation of collaborative R\&D networks between European regions, particularly through the use of the Exponential Random Graph Models (ERGM) model, while Wanzenböck et al. suggest looking not at collaboration choices but at the determinants of regions' positions in the network, and more particularly their degree of centrality. For the first time, Wanzenböck et al. also explore the issue of the nature of networks by comparing three different collaborative networks (co-inventions, co-publications and cooperation in EU Framework Programmes).

\subsection{From forming networks to performance}

Research has been undertaken on the impact of partnerships on innovative performance, but little has been done on the significance of position within the network. There are, in fact, many studies on network position and various aspects of firms' performance in the management literature. However, this work concentrates on nodelevel performance rather than on the network as a whole (aggregate (local) network

\footnotetext{
${ }^{2}$ See research developed by the French group 'Dynamiques de Proximité' [Dynamics of Proximity] and the special issue of Regional Studies edited by Boschma (2005).
} 
level). A few studies examine the relationship between network structure and regional performance (Sebestyén and Varga 2013; Périac 2014), and they tend to find that differences in network structures explain (at least in part) differences in innovation performance at the regional level. However, it is often difficult to find convincing results in these studies, as they face two major research challenges, both of which are largely unresolved.

- The first consists of taking account of the asymmetry of relationships between actors within cooperative networks. Very often, because of the difficulty of obtaining systematic information on the real content of cooperative relationships measured by co-inventors, co-publications or R\&D collaborative projects, network data are built on the assumption that a partnership either exists or not and take no account of the nature or intensity of exchanges of knowledge within it. Often, affiliation networks representing multi-partner research consortia are projected onto a onemode network based on the very strong assumption that all members of a consortium are considered to interact equally with all other members. In this special issue, Maggioni et al. address this question by using FP data to study the impact of members' respective positions within the same consortium. This does not refer to the characteristics of the network, in the sense of analysing social networks, but rather to the nature of the role played by the partner within the consortium. This opens up very interesting avenues for research which go beyond network position and aim to explore the nature of relationships and exchanges between network partners.

- The second research challenge involves the connection between the determinants and impact of partnerships. The study of the impact of collaborations and the study of the determinants of partnerships are subject to two distinct literatures, which prevent comparison of results. ${ }^{3}$ In particular, do different forms of proximity have the same impact upon the formation of relationships and how do these relationships affect performance? The article by Plunket and Cassi explores this issue. Their research is also interesting as it simultaneously takes account of different forms of proximity. Previously, when it came to the question of performance, different forms of proximity (spatial, technological, social, etc.) had only been studied separately.

Designing a more integrated analysis of how collaborative networks are formed and their impact upon innovative performance clearly raises not only methodological issues, but also questions about economic analysis. This is one of the issues addressed here by Billand et al., in a theoretical examination of the microeconomics of innovation, in order to ask how the dynamics of R\&D networks affect competitive relationships among innovative firms. Although, overall, it has been demonstrated that network structure has an impact upon firms' and regions' performance depending on their network position, the question of whether or not decision-makers have the tools to create (or induce other to create) these efficient networks remains. What decisionmaking abilities do private actors have and what is the role of the public sector in these processes? Answers to these questions have not yet been formulated. A solid theoretical framework is therefore required to represent the processes at work, which

\footnotetext{
3 With the exception of Broekel and Boschma (2012).
} 
differ depending on the nature of the networks in question and on the performance sought after, for both firms and regions.

\section{Content of this special issue}

To analyse these questions, this special issue includes one theoretical article, one methodological article and four empirical articles.

The theoretical article by Billand et al. studies the formation of R\&D collaborative networks using a network formation model along the lines of Goyal and Joshi (2003), but within which firms compete in several markets at the same time. It shows that equilibrium networks do not coincide with efficient networks. Efficient networks are characterised by a single component within which firms are very close (direct or indirect relationships, but with a maximum distance of 2), equilibrium networks include situations where there are no partnerships at all, even when there are no costs of forming relationships. These situations, resulting from firms' multi-market strategies, may therefore lead to partnerships which are less frequent than is socially desirable. These results thus strengthen the idea that public incentives to creating R\&D partnerships may be necessary and imply that differences are likely to exist between 'spontaneous' R\&D collaborative networks and those encouraged by public authorities. From an empirical point of view, comparing the different types of networks which involve public policies to varying degrees (for example, co-patents are determined to a greater extent by firms' strategies, while R\&D collaboration programmes are driven by the European Commission's policy), may be a way to observe these differences.

Without claiming to examine all these questions, the empirical articles in this special issue seek to identify the determinants of different types of collaborative R\&D networks, as well as the impact these networks have on innovative performance. Any such analysis, however, raises specific methodological difficulties. In order to understand these difficulties and to assess how different statistical approaches can overcome them, the article by Broekel et al. presents a panorama of the main techniques for analysing the formation of knowledge networks. The authors identify four strategies: traditional gravity models, stochastic actor-oriented models, quadratic assignment procedures, and Exponential Random Graph Models. These strategies differ in their ability to take account of different forms of proximity and their impact on the evolution of knowledge networks. This explains why the four empirical articles which follow use different methodologies, because of the nature of the data and the networks which they are studying.

In terms of the data used, it should be noted that with the exception of the article by Plunket and Cassi, and in contrast to the theoretical work put forward by Billand et al. which relates to microeconomic entities, the empirical work in this issue focuses on the regional scale. This is due, on the one hand, to data availability constraints and, on the other, to the decision to adopt a spatial perspective. Despite the development of localised data on innovation and collaboration on the microeconomic scale, it remains difficult to collate individual data covering all the properties of agents and their interactions needed to assess the formation and impact of R\&D networks. The rare attempts at microeconometric analysis of $\mathrm{R} \& \mathrm{D}$ collaborative networks struggle 
to take account of all the mechanisms at work. For example, Hanaki et al. (2010) use data from collaborative inventions to analyse relationships between partners, but they find it difficult to account for firms' research efforts. For most firms, R\&D expenditure is not publicly available. Consequently, Hanaki et al. (2010), as well as Plunket and Cassi in this issue, and the literature on collaborative invention more generally, estimate the intensity of R\&D through the number of patents. Similarly, in their attempts to estimate the determinants of inter-firm partnerships within European Framework Programmes, Autant-Bernard et al. (2007) and Hazir (2013) are limited in ability to account for the effects of technological potential, because the only information available relates to project budgets, rather than the overall amount firms invest in R\&D. To our knowledge, outside the management literature, very little research on individual agents takes into account both collaborative research relationships and the specific individual characteristics of actors. This is all the more true when it comes to simultaneously comparing several types of collaborative network, as is the case in this special issue (co-invention, co-publication, R\&D co-operation, etc.). The lack of a single identification code, common to all databases, prevents work on the individual level and restricts analysis to an aggregate level. It is therefore necessary to use regional data in order to take into account the determinants of how R\&D networks are created and perform. In addition, one of the objectives of this special issue is to pay particular attention to the role of different forms of proximity, and particularly the role of spatial distance. From this point of view, the region is a relevant entity.

Against this backdrop, Hazir and Autant-Bernard analyse the regional and spatial characteristics which explain the overall architecture of the network. The article adopts an ERGM approach in order to study the role of different forms of proximity on the formation of $R \& D$ collaborative networks between European regions. The use of this type of model goes beyond approaches which examine the formation of bilateral relationships, by introducing different forms of dependency between the relationships. This approach, which focuses upon the overall structure of the network, highlights the role of contiguity, not only in the creation of relationships between two regions, but also in the creation of triads. Triads most often connect one distant region with two others which are spatially close. The creation of long-distance relationships is therefore not independent of the creation of proximal relationships, reflecting a form of complementarity between these different dimensions.

Analysing the effects of proximity on network structure is also at the heart of the article by Wanzenböck et al, although this differs from the preceding article in a number of ways. First of all, the aim of the article is not only to explain the overall structure of the network, but the position occupied by each region within the network and, more precisely, in terms of the centrality of the region. Wanzenböck et al. compare the structure of different networks and focus on the characteristics which determine regions' ability to integrate into them. The article also adopts a different methodology than the previous article, with the authors opting for a spatial econometrics approach. This paper thus aims to compare the structure of different knowledge networks and to evaluate the respective role of characteristics which are internal and external to the region in these different networks. It highlights that the determinants of regional integration in knowledge networks vary depending on the nature of the network. Spatial 
spillovers play a more significant role in co-invention networks and R\&D collaboration within EU framework programmes than in co-publication networks.

This variable role of proximity is examined from a complementary perspective in the article by Plunket and Cassi. While Wanzenböck et al. study the role of proximity in the creation of different knowledge networks, Plunket and Cassi compare, within co-inventors' networks, the role played by proximity in the creation of relationships to the role it plays on innovative performance. They observe that different forms of proximity (relational, technological, organisational, and spatial) do not have the same impact upon the creation of relationships and regional performance in terms of innovation. While geographical proximity facilitates the creation of relationships, it does not increase the impact collaboration has upon innovation. In other words, the most likely relationships are not the most effective. Other forms of proximity between inventors, such as relational and organisational proximity, have a stronger impact on innovative performance. The technological proximity of co-inventors appears to produce an inverted U-curve effect on innovative performance.

Also using data on co-inventions, Maggioni et al. take a closer look at the determinants of innovative performance by analysing the mechanics of knowledge diffusion within R\&D consortia and their impact upon regions' propensity to patent. To do so, they use a methodology which takes into account the role of actors within the network, and the weight and direction of relationships. Their approach makes it possible to compare the parameters of self-correlation associated with each type of relational structure. The results thus highlight the hierarchical and asymmetric nature of the diffusion of knowledge within European Framework Programmes, with project coordinators at the centre of knowledge flows. This work also highlights the methodological limitations which remain to be overcome in order to acquire a more refined understanding of the mechanisms by which knowledge is diffused within networks. By using relational rather than simply spatial matrices, the assumption of the exogeneity of the weight matrices upon which standard spatial econometrics tools are based can be dismantled. As such, addressing the problem of the endogeneity of relational matrices is a major methodological challenge.

\section{Conclusion}

The formation of cooperative networks creates promising externalities in terms of innovative performance, but the research conducted on these networks shows that gaps may exist between networks resulting from individual actors' strategies (often marked by the competitive dynamics within which these actors are situated when using innovations from R\&D partnerships), and networks seen as effective or efficient in terms of $\mathrm{R} \& \mathrm{D}$, innovation and the position of territories (region, nation, Europe) in global competition through innovation. These gaps leave scope for public policy intervention, and although the articles in this special issue do not focus on these questions, they do open up some interesting avenues for future research.

First, encouraging co-operation in R\&D may be relevant when firms are competing in markets. Second, favouring co-operation over greater geographical or technological distances and the creation of 'social proximity' within networks (mobility of 
researchers) may limit the negative effect on performance stemming from too strong geographical or technological proximities or from the lack of ability to absorb as a result of a lack of 'social proximity'. In this sense, the Framework Programmes (FPs) have already proven to be effective, as FP networks appear to be 'freer' of the constraints of pre-existing spatial structures than patent networks, which are notably much more marked by the impact of firms' strategies.

However, it is important to take into account the characteristics of the diffusion of knowledge within the partnership and, particularly, the hierarchical nature of R\&D partnership networks. Indeed, the 'integrating' effect of FPs for the various regions loses much of its meaning when the hierarchical nature of networks and, particularly, the role of coordinators as the real nucleus of knowledge diffusion are taken into consideration. In this context, the FPs' objectives in terms of innovation and cohesion policies appear to contradict one another.

Finally, ongoing differences between regions' capacities to integrate and actively participate in publicly supported networks, such as the FPs, indicates that there is still an important role for local policy in creating the conditions for actors in a region to obtain a central position in R\&D cooperation networks. Beyond simply encouraging the creation of networks, the research presented in this issue demonstrates the importance of internal characteristics and resources: population and economic potential for FPs, R\&D financial resources for publication networks, and human resources for patent networks. This implies not only understanding the determinants for regions to enter networks actively, but really understanding the impact of their own performance. From this point of view, a great deal remains to be done. As Broekel et al. stress, the models previously used to discuss the relationship between networks and the geography of innovation "mainly focus on bringing (exogenous) geography into (endogenous) knowledge networks: analysing endogenous regional development from (also endogenous) knowledge networks seems to be a major challenge for future research". This issue presents the first contributions towards this goal.

Open Access This article is distributed under the terms of the Creative Commons Attribution License which permits any use, distribution, and reproduction in any medium, provided the original author(s) and the source are credited.

\section{References}

Autant-Bernard C, LeSage J, Massard M (2007) Spatial econometrics, innovative networks and growth, introduction to the special issue. Annales d'Economie et de Statistiques 87-88:1-7

Bergman E, Maier G (2009) Embedding network analysis in spatial studies of innovation. Ann Reg Sci 43(3):559-565

Boschma R (2005) Role of proximity in interaction and performance: conceptual and empirical challenges. Reg Stud 39(1):41-45

Breschi S, Lissoni F (2009) Mobility of skilled workers and co-invention networks: an anatomy of localized knowledge flows. J Econ Geogr 9(4):439-468

Broekel T, Boschma R (2012) Knowledge networks in the Dutch aviation industry: the proximity paradox. $\mathrm{J}$ of Economic Geography, Oxford University Press, 12(2):409-433

Cloodt et al. (2006) The strength of R\&D network ties in high-tech industries: a multi-dimensional analysis of tie strength on technological performance. In: Proceedings of the Danish Research Unit for Industrial 
Dynamics (DRUID) Summer Conference, Copenhagen Business School, Copenhagen, Denmark, June 18th-20th, 2006, 11th Annual Meeting

Goyal S, Joshi S (2003) Networks of collaboration in oligopoly. Games and Economic Behav. Elsevier, 43(1):57-85

Hanaki N, Nakajima R, Ogura Y (2010) The dynamics of R\&D network in the IT industry. Research Policy, Elsevier, 39(3):386-399

Hazir CS (2013) Multilateral R\&D Collaboration: an ERGM Application on Biotechnology In: the geography of networks and R\&D collaborations.T. Scherngell (ed) 2013, Springer, series Advances in Spatial Science 221-238.

Newman M (2004) Coauthorship networks and patterns of scientific collaboration. Proc Natl Acad Sci 1001:5200-5205

Périac F (2014) Les concepts de diversité culturelle et de capital social comme facteurs explicatifs de la capacité d'innovation des organisations et des territoires, Thèse de doctorat, pp 408

Powell WW, White DR, Koput KW, Owen-Smith J (2004) Network dynamics and field evolution: the growth of interorganizational collaboration in the life sciences. Am J Sociol.110(4):1132-1205

Roijakkers N, Hagedoorn J (2006) Inter-firm R\&D partnering in pharmaceutical biotechnology since 1975: trends, patterns, and networks. Res Policy 33:1153-1165

Sebestyén T, Varga A (2013) Research productivity and the quality of interregional knowledge networks. Ann Reg Sci 51(1):155-189

Wagner C, Leydesdorff L (2005) Network structure, self-organisation, and the growth of international collaboration in science. Res Policy 34:1608-1618 